\title{
Representação midiática do impeachment brasileiro em 2016: o dito e o não dito ${ }^{1}$
}

\author{
Phillipe Farias Ferreira² \\ Maiara Sobral Silva ${ }^{3}$ \\ Kelinne Oliveira Guimarães ${ }^{4}$
}

\begin{abstract}
Resumo: $\bigcirc$ estudo visa analisar 0 tratamento mediático no que se refere aos motivos que levaram ao impeachment da ex-presidente brasileira Dilma Rousseff. No sentido de discutir se essa representação midiática do referido impedimento foi realizada por meio de dados consolidados ou se apenas foi focada em uma abordagem mítica, baseada em mentiras, falácias, suposições e informações truncadas. Para isso, observou-se as edições do jornal Folha de São Paulo, versões impressas disponíveis na página do veículo, como recorte foi escolhido o mês de agosto de 2016, uma vez que a votação final do processo aconteceu no dia 31 deste mês.
\end{abstract}

Palavras-chave: Impeachment Dilma Rousseff. Crime de Responsabilidade Fiscal. Pedaladas Fiscais. Representação Midiática.

\section{Introdução}

O Brasil passou por muitas mudanças sociais, políticas e econômicas nos últimos anos sofreu as consequências da crise econômica vivida pelos Estados Unidos em meados de 2007, mas a política econômica interna que foi a motivadora do pedido de impeachment da ex-presidente Dilma Rousseff, visto que os créditos suplementares e as pedaladas fiscais

'Trabalho apresentado no GP Teorias do Jornalismo, XVII Encontro dos Grupos de Pesquisas em Comunicação, evento componente do $40^{\circ}$ Congresso Brasileiro de Ciências da Comunicação - Intercom 2017

2Phillipe Farias Ferreira é Graduado em Ciências Econômicas pela Universidade Federal de Campina Grande -UFCG (2004) e Pós-Graduado no MBA em Gestão Estratégica Avançada de Negócios da Universidade Federal de Alagoas - UFAL em 2008. Mestre em Economia, com área de concentração em Desenvolvimento Regional e Gestão de Empreendimentos Locais da Universidade Federal de Sergipe - UFS em 2011. Atualmente é docente no Instituto Federal do Tocantins (IFTO).

${ }^{3}$ Maiara Sobral Silva é Jornalista pela Universidade Federal do Tocantins (UFT) e mestre em Educação pela Universidade Federal de Santa Maria (UFSM). Atua como jornalista na área de assessoria de comunicação do Instituto Federal do Tocantins (IFTO) desde o ano de 2010. Lecionou como professora convidada as disciplinas de Introdução à Fotografia e Introdução à Antropologia Cultural na UFT. Além das pesquisas na área de formação de professores e educação a distância, também estuda os sistemas de controle social: e-OUV e e-SIC, com foco na abordagem da transparência informacional na Administração Pública.

${ }^{4}$ Kelinne Oliveira Guimarães é jornalista no Instituto Federal do Tocantins-IFTO, possui graduação em Comunicação Social com habilitação em Jornalismo pela Fundação Universidade Federal do Tocantins-UFT, mestranda no Programa de Pós- Graduação em Educação Profissional e Tecnológica. Tem experiência na área de Comunicação, com ênfase em jornalismo no departamento de assessoria de comunicação, já foi aluna de iniciação científica, monitora bolsista e participou de projeto de extensão, enquanto estudante da UFT. 
foram as justificativas para solicitação de tal impedimento, o que corrobora que o pedido foi solicitado em função de critérios adotados na política econômica interna.

Durante todo o processo de impeachment foi possível perceber que parte do conhecimento do grande público sobre o assunto é oriundo do discurso midiático. De acordo com Walter Lippmann (2008), boa parte do conhecimento que as pessoas adquirem sobre política provém do que é transmitido a elas pelos meios de comunicação. A referência da opinião pública a respeito do que acontece nos grandes centros de deliberação política, aos quais a maior parte da população não tem acesso, advém do trabalho realizado pela grande mídia. A imprensa, um aparelho dotado de hegemonia, como afirma Gramsci (2002), é quem faz a mediação dos acontecimentos da sociedade política para a sociedade civil, por vezes, atuando como um partido político na defesa de seus interesses políticos e econômicos.

Dessa forma, os jornais estão também construindo um lugar de fala de extrema importância dentro da sociedade brasileira por interferirem em uma dada realidade a partir da visibilidade que dão a determinados fatos.

Neste cenário, surgiu a ideia de analisar a representação midiática do impeachment em 2016.

\section{Governo Dilma e impeachment}

A crise, os escândalos envolvendo o PT e o descontentamento com o governo culminaram com um protesto nacional, no dia 15 de março. Na ocasião, entre várias manifestações contra o atual governo, o destaque foi para os pedidos de saída de Dilma Rousseff da presidência do país. Porém, a grande crítica feita por parte da imprensa e por alguns cientistas políticos foi em relação à falta de consciência política dos manifestantes. Em meio aos gritos de "fora Dilma" existiam muitos manifestantes pedindo o impeachment presidencial e até mesmo a intervenção militar. Muitos dos que pediam o impedimento acreditavam que haveria novas eleições ou que Aécio Neves assumiria a presidência. Segundo pesquisa do instituto Data foIha 5 , 63\% dos brasileiros defendiam o processo de impeachment contra a petista, sendo que apenas 37\% destes sabiam que o cargo seria assumido pelo vice-presidente.

Desde a eleição da presidente em outubro de 2014, vários partidos políticos e entidades da sociedade civil ingressaram com recursos para impedirem sua posse, após empossada, Dilma Rousseff continuou sendo alvo de representações. Até que no dia 2 de dezembro de 2015, o então presidente da Câmara dos Deputados, Eduardo Cunha, autorizou a abertura do processo de impeachment.

O presidente acolheu o pedido dos juristas Hélio Bicudo e Miguel Reale Júnior, que na petição alegaram, principalmente, o cometimento de dois crimes: descumprimento da Lei de Responsabilidade Fiscal por edição de decretos liberando crédito extraordinário, em 2015, sem o aval do Congresso Nacional e a prática de atrasar repasses a bancos públicos a fim de cumprir as metas parciais da previsão orçamentária, também conhecidas como "pedaladas fiscais".

A Câmara dos Deputados aprovou no dia 17 de março de 2015, em votação aberta, por 433 favoráveis e apenas 1 voto contrário, a instalação da Comissão Especial do Impeachment. A comissão foi composta por 65 integrantes, entre governistas e opositores, e avaliou o pedido de impeachment por crime de responsabilidade.

Após oitivas das testemunhas de defesa e de acusação, o relator dessa comissão, deputa-

5Disponivel em: http://www7.folha.uol.com.br/poder/2015/04/1615424-maioria-quer-impeachment-de-dilma-. 60 e-nao-conhece-vice.shtml>. Acesso em: 4 mai. 2017. 
do Jovair Arantes apresentou relatório favorável ao impedimento, os deputados deliberaram sobre o voto do relator no dia 17 de abril de 2017. Naquele momento, a câmara autorizou a instauração do processo de impeachment com 367 votos a favor e 137 contra.

\title{
Jornalismo e Economia: mitos e verdades
}

Jornalismo e Economia são duas áreas que se encontram com habitualidade, mas nem sempre esse encontro promove compreensão aos receptores da notícia, tanto que Kucinski (2007, p.14) alerta para um desafio no que tange ao jornalismo econômico:

\begin{abstract}
Com tudo isso, uma grave disfunção afeta o jornalismo dedicado à economia. A maioria dos leitores e dos telespectadores, mesmo os instruídos, como os estudantes universitários, não consegue decodificar o noticiário econômico. Para o grande público, a economia adquiriu, ao mesmo tempo, significados elementares, ligados ao seu dia-a-dia, e outros abstratos, de difícil compreensão. O desafio de traduzir processos econômicos complexos em linguagem acessível não foi vencido, seja porque os processos econômicos se definem num outro plano de saber que não o do saber convencional, seja devido à sua instrumentalização ideológica crescente.
\end{abstract}

Outro alerta feito pelo autor é quanto à formação dos leitores e jornalistas, além disso, ele ressalta que no Brasil não há um número considerável de publicações jornalísticas que façam a análise da Economia, como destaca:

No Brasil, essa disfunção foi acentuada pelas deficiências na formação tanto de jornalistas como de leitores, pelos obstáculos à prática do jornalismo e pelo número reduzido de publicações voltadas à macroeconomia e à economia política, em comparação com países de dimensões semelhantes (KUCINSKI, 2007, p. 15).

Sendo assim, é preciso repensar as formações, não dos jornalistas, como do público que receberá as notícias, com foco em uma discussão analítica da macroeconomia e da economia política, não apenas de dados ou depoimentos, ou seja, compilações e resumos.

As editorias de economia, ao aproximarem as narrativas sobre fatos econômicos das notícias policiais, além de publicarem matérias explicando as medidas de alteração nessa esfera no país, buscaram uma extrema popularização na cobertura de economia no período. Bird e Dardenne (ibid., p. 275), citando Sperry (1976), explicam que "na produção jornalística os jornalistas não se limitam a utilizar definições culturalmente determinadas, mas também têm de encaixar novas situações em velhas definições. Está no seu poder a colocação de pessoas e acontecimentos em categorias existentes de herói, vilão, bom e mau, e, assim, empossar as suas "estórias" com a autoridade mitológica".

Lillian Witte Fibe começou a cobrir economia no jornalismo impresso, como repórter na FoIha de São Paulo, onde entrou em 1973, quando ainda estava no segundo ano do curso superior nessa área na USP. Em 1975, ela foi trabalhar na editoria de Finanças da Gazeta Mercantil. Entre outubro de 1982 e dezembro de 1983, ela apresentou um programa diário chamado Dinheiro, de quatro minutos de duração e que ia ao ar de madrugada, um tempo que a Gazeta Mercantil comprava da Bandeirantes. Em janeiro de 1984 foi convidada para ser repórter de economia da TV Globo, inicialmente no Jornal da Globo e, em seguida, no Jornal Nacional.

Dessa forma, os jornais estão também construindo um lugar de fala de extrema importância 
dentro da sociedade brasileira por interferirem em uma dada realidade a partir da visibilidade que dão a determinados fatos. Essas seções destinadas a questões de utilidade para os leitores estão também relacionadas com um tipo de jornalismo que começou a ser valorizado no contexto de final do século XX. Abreu (2003) registra que, entre os profissionais de comunicação, especialmente entre os jornalistas da imprensa escrita, começou a prevalecer nessa época o conceito de "utilidade social" da mídia, ideia que identifica a ação jornalística como dirigido a servir aos interesses concretos dos cidadãos, a responder às preocupações dos seus leitores ou de sua audiência - seria o "jornalismo cidadão". Estudar as práticas da imprensa de economia implica estudar o consumo cultural porque analisamos e refletimos, principalmente, sobre a cobertura realizada por um produto cultural (o jornal impresso), que se molda para atender ao público-leitor e estabelecer mediações com ele.

\section{Análise da folha de São Paulo}

O jornal Folha de São Paulo é um jornal impresso veiculado diariamente no Brasil, segundo dados do Instituto Verificador de Circulação (IVC) é o jornal impresso com maior circulação no país. O IVC levantou que em 2015 foram comprados cerca de 316.860 exemplares em dias úteis e 344.022 exemplares aos domingos, dia que a publicação tem um caderno especial.

Tais números motivaram a escolha pelo referido jornal, sendo que para analisar a abordagem e representação midiática do impeachment foi adotado o critério de análise das edições do mês de agosto de 2016, visto que a votação final do processo aconteceu no dia 31 deste mês. Vale lembrar que foram analisados os primeiros cadernos da publicação.

O vocábulo impeachment foi encontrado em 25 edições do jornal, detalhe para a frequência do termo a partir do dia 7 de agosto, uma vez que deste dia até o dia 31, todas as edições contêm menção ao processo de impedimento.

Ao analisar as edições, foram encontrados 224 textos com menções ao impeachment, o que chama atenção nesse levantamento é o número de citações em notas, editoriais e comentários de leitores, fora em 146 publicações, seguidas de 46 matérias com imagens, 26 matérias sem imagens e quatro entrevistas. Na capa do jornal, o impedimento apareceu 13 vezes. Nesse levantamento, fotos, infográficos, tabelas, gráficos foram considerados imagens

O número tão superior de notas, editoriais e comentários de leitores demonstra uma tendência do jornalismo moderno, que em função do enxugamento das equipes e da instantaneidade da globalização, está cada vez mais sucinto e focado em opiniões de editores, colunistas e leitores.

Os resultados obtidos são ancorados nos estudos de enquadramento, entendendo estes não apenas como um método de análise, mas como um conceito norteador que possibilita uma compreensão geral do objeto analisado. Além de um breve levantamento histórico do uso dos enquadramentos como processo teórico e metodológico, o texto aponta e justifica a escolha da operação de análise da presente pesquisa, no caso a proposta de Gamson e Modigliani (1989) de "pacotes interpretativos". Os autores explicam que, por meio dos elementos encontrados em um texto, tem-se um conjunto de dados que dão a ideia organizadora central do discurso, o quadro ou frame.

Portanto, o presente estudo permitirá identificar quais os enquadramentos utilizados pelo jornal Folha de São Paulo para representar os acontecimentos que envolvem a crise do governo que, no momento, tinham como ápice os protestos, os quais se espalharam por todo o país e cujos manifestantes, dentre outras mudanças, pediam o impeachment da Presidente.

A busca pelo "furo de reportagem", mesmo que em tempos da notícia em tempo real, tem feito muitos veículos publicar informações, ao invés de trabalhos investigativos e analíticos. A informação sem uma abordagem crítica não produz conhecimento, e esse é um dos poréns da atualida- 
de, há uma chuva de informações, mas não há o processamento dessas em conhecimento.

Na edição do dia 26 de agosto, dois enxertos de uma matéria apócrifa, devem ser levados em consideração, são eles: "Não é segredo que a economia brasileira estagnou-se em 2014. com arrecadação em queda, o governo passou a dispor, a partir daquele ano, de menos dinheiro que o necessário para a almejada expansão das despesas". E em: "A fim de ocultar o estado calamitoso das contas públicas - e assim aumentar os gastos públicos e a chance de reeleição da petista-, o governo recorreu às pedaladas, expediente que pode ser comparado a um abuso do cheque especial".

Tais alegações são feitas por uma pessoa sem nome e sem um dado concreto, pela forma com que as informações são dispostas, elas podem ser consideradas opiniões de quem escreveu, pois não existe uma relação entre a causa e a consequência, não existe uma análise econômica ou até mesmo levantamentos quantitativos

O jornalismo opinativo é uma das formas de redação, mas não deve ser utilizado como fonte de matéria, ou seja, o veículo precisa deixar claro que ali está a opinião de um colunista, de um articulista, de um ensaísta, mas esse não é um caso dos trechos analisados, uma vez que nem assinaram a matéria.

Outro dado interessante a ser analisado é que a maioria das matérias trazem fontes oficiais para falar sobre o impeachment, seja o presidente interino Michel Temer, seus ministros, a ex-presidente Dilma Rousseff e seus ex-ministros, enfim, são publicações baseadas em declarações de quem está dentro do processo, o que catalisa a imparcialidade das declarações.

Essa imparcialidade fica evidente em alguns títulos das matérias levantadas, como estas: "Economia vai legitimar Temer, diz aliado", publicada no dia 21 de agosto, "Temer diz já ter votos para o impeachment de Dilma", no dia 25 de agosto e "Temer conta com juro menor só em 2017", publicada no dia 31 de agosto.

Imagem 1: Página da edição do dia 25 de agosto de 2016
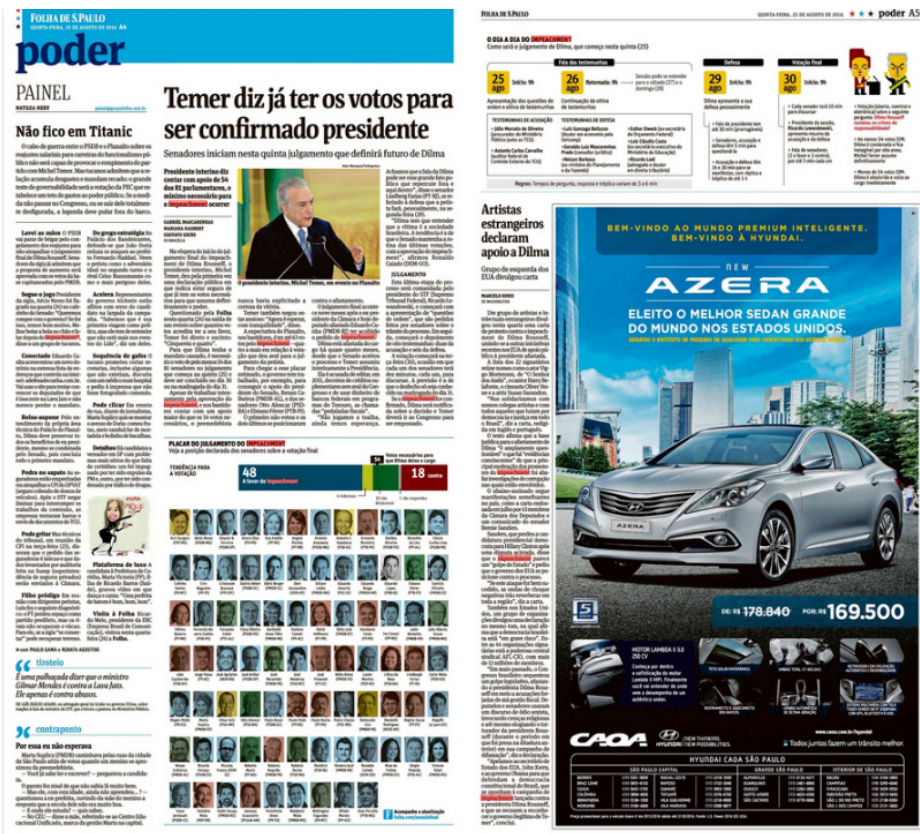

Reforçando a análise anterior, como fica perceptível na Imagem 1, a abordagem jornalística demonstra elevado grau de redação declaratória, uma vez que deixa a contagem dos votos para um dos maiores beneficiados com o impeachment, o presidente interino Michel Temer. 
Desta forma, é preciso repensar as fontes utilizados, como já dito anteriormente, a questão não é deixar de lado as fontes oficiais, ou seja, as fontes envolvidas. Mas sim, esclarecer os dois lados da situação, promover uma análise crítica e permitir ao leitor que faça a sua própria conclusão e não traga a conclusão pronta.

Tais destaques deixam evidente a necessidade de um novo pensamento no que tange ao jornalismo, essa reformulação precisa passar pelos bancos das universidades, pelas mentes dos empresários do ramo e pelas consciências dos leitores e telespectadores. Visto que o público receptor dessa informação, está acostumado com essa abordagem tendenciosa, é preciso uma mudança de cultura na recepção, para que haja uma mudança de cultura na emissão.

Sendo assim, essa falta de uma análise socioeconômica, focada em dados e estudos quantificáveis, fomenta a desinformação dos receptores dessa notícia. O mais pontual nesse caso é que o leitor acredita que está consumindo uma informação útil, pois está lendo um veículo renomado e com relevante histórico, porém, na verdade, ele tem acesso à compilação de declarações, o que não gera conhecimento, mas especulação.

Continuando a análise das edições do mês de agosto de 2016, foram adotados dois filtros de busca: pedaladas fiscais e crime de responsabilidade fiscal. O primeiro termo apareceu em 11 edições do jornal e o segundo foi encontrado em apenas uma edição.

Em relação às menções aos termos supracitados, foram identificados 20 textos, dos quais nove eram comentários, editoriais ou notas, sete eram matérias com imagens, três matérias sem imagens e uma entrevista.

Um fator a ser considerado, é que ao falar de termos tão específicos, dos 20 textos, nenhum trouxe uma análise ou depoimento de fonte externa ao processo de impedimento, ou seja, todas as produções textuais foram produzidas com base em fontes ligadas ao impeachment.

Quais fontes são essas? O presidente interino Michel Temer, a ex-presidente Dilma Rousseff, ministros, ex-ministros, deputados federais e senadores. Sendo assim, é muito difícil encontrar uma análise que não seja tendenciosa, pois cada um dos envolvidos tinha algo a perder ou a ganhar, dependendo do resultado da votação.

Das 20 citações encontradas, 10 trazem citações ou depoimentos dessas fontes citadas anteriormente e 10 nem citações ou depoimentos trazem, tornando o texto em uma compilação de fatos, ou seja, um resumo.

No dia 3 de agosto de 2016, a edição da Folha de São Paulo traz uma matéria com o seguinte enxerto:

Nesta terça, o relator do processo de impeachment, Antônio Anastasia (PSDB-MG), apresentou na comissão especial relatório favorável à saída definitiva de Dilma. No parecer, o tucano afirma que há provas de que houve crime de responsabilidade na abertura de créditos suplementares sem autorização e nas pedaladas fiscais.

Na matéria que traz a citação destacada, não há explicações do que vem a ser os tais créditos suplementares e as pedaladas fiscais, a abordagem é muito superficial, o que causa a reverberação do termo por parte dos leitores, mas o que pode ser estudado em uma pesquisa posterior é se a população brasileira compreende o que seja essas pedaladas fiscais e os créditos suplementares.

Ainda nessa matéria, as citações ou depoimentos apontados são dos envolvidos do processo, relator, acusada, enfim, não existe uma análise externa. É sabido que a imparcialidade jornalística tem sido muito debatida pelos profissionais e estudiosos da área, uma vez que cada ser, por ser social, traz consigo uma bagagem subjetiva que influencia na sua produção textual. 
No entanto, um analista externo ao processo, traria uma visão mais técnica, daí caberia ao jornalista esclarecer esses termos aos leitores, para evitar os achismos e compilações de fatos.

Já no dia 10 de agosto, uma matéria traz o seguinte trecho: "Dilma é acusada de editar três decretos de créditos suplementares sem aval do Congresso e de usar verba de bancos federais em programas que deveriam ser bancados pelo Tesouro, as chamadas "pedaladas fiscais".

O tom genérico das publicações, como pode ser observado em "programas que deveriam ser bancados pelo Tesouro", demonstra que a intenção da matéria não é esclarecer os motivos das acusações, mas informar o ato de acusar.

Desta forma, não há esclarecimento sobre quais seriam esses programas, do porquê deveriam ser bancados, quais os motivos de não bancar, o que levou a esse desvio e se essa era prática de outros governos.

Além da abordagem superficial nas matérias sobre o que foram as pedaladas fiscais e os créditos suplementares, existe também um caráter descontextualizado no que tange aos editoriais e às colunas de opinião, como se observa no enxerto da edição do dia 27 de agosto

Não culpe os outros (golpe das elites) ou as circunstâncias (crise internacional). Investigue seus erros, sobretudo um, que interessa ao futuro da convivência democrática no Brasil. Refiro-me ao sectarismo. Mais que às 'pedaladas fiscais' ou ao escândalo na Petrobras, sua derrota final deve-se ao sectarismo.

Outro dado interessante nesse levantamento, é que na semana final que antecedeu a votação, foi criada uma coluna remetendo ao impedimento do ex-presidente Fernando Collor, a coluna foi intitulada: "Enquanto isso, em 1992.... Tal paralelo reforça o caráter sensacionalista da abordagem midiática em relação ao impeachment de Dilma Rousseff.
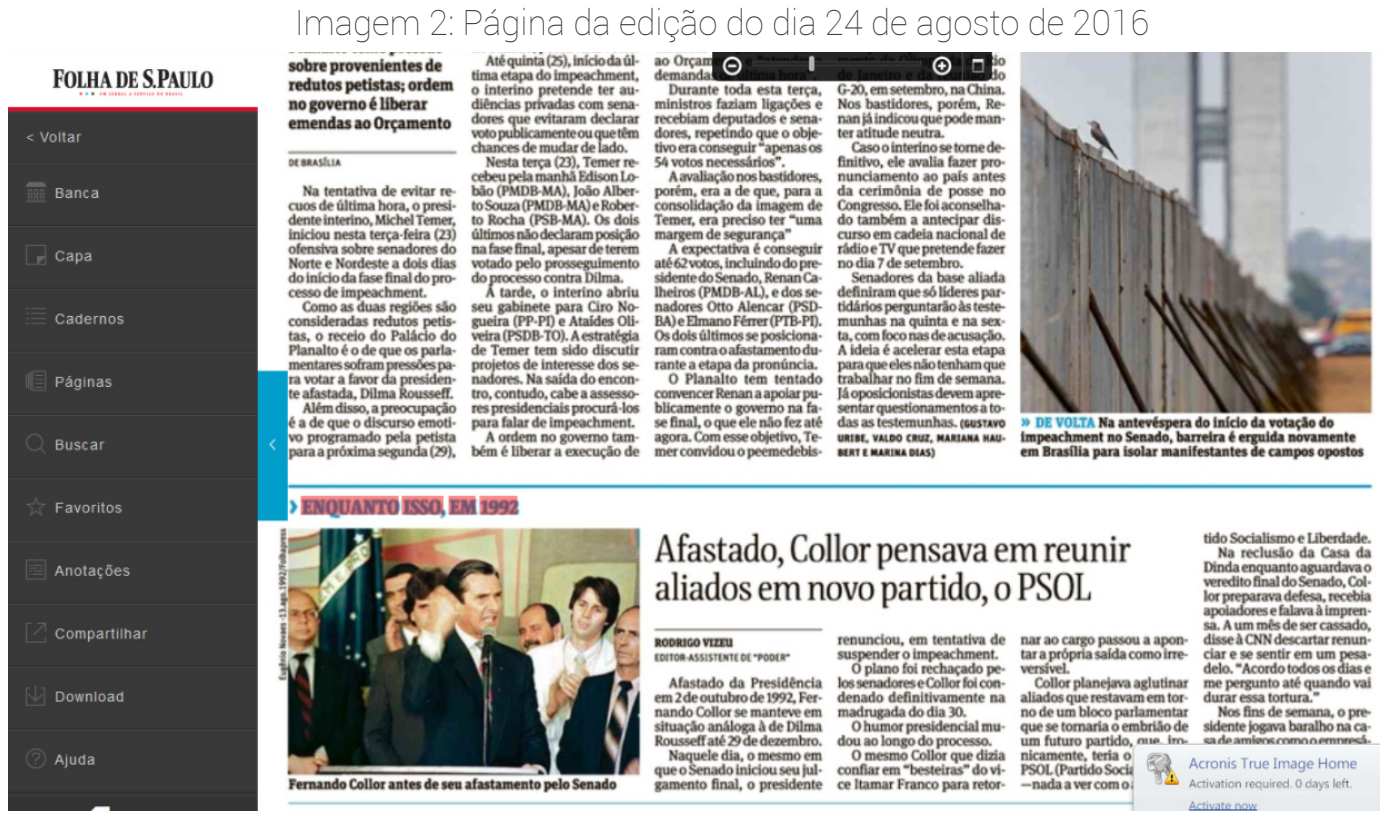

Como dito anteriormente e retratado pela Imagem 2, a coluna Enquanto Isso, em 1992 retrata os últimos passos da caminhada do ex-presidente Fernando Collor no primeiro processo de impedimento que marcou a República do Brasil. Essa comparação é interessante, mas ao mesmo tempo, superficial, pois não traz elementos de análise crítica, mas um passo a passo do que ele estava vivendo. 
Ao tratar os dois processos de impedimento, não há uma comparação sobre as responsabilizações dos acusados, sobre as manifestações nas ruas e o cenário socioeconômico interno e externo, é simplesmente uma compilação cronológica e declaratória

Por fim, a Imagem 3, última citação do impeachment em 31 de agosto de 2016, finaliza a abordagem sobre o processo com uma matéria não muito positiva no que diz respeito à economia, pois fala que a previsão do presidente interino Michel Temer é que os juros caiam somente em 2017, mas ao mesmo tempo traz uma foto muito positiva, na qual Temer está sorrindo, entre o presidente do Banco Central Ilan Goldfajn e o ministro Henrique Meirelles.

Essa última matéria reforça como foi a abordagem sobre o processo de impedimento, e não cabe uma análise semiótica da imagem no momento, mas como muitas pessoas não leem a matéria e apenas visualizam a imagem, essa foto leva o receptor a entender que está tudo bem, mesmo com a "resistência da inflação e demora no ajuste fiscal".

Imagem 3: Página da edição do dia 31 de agosto de 2016

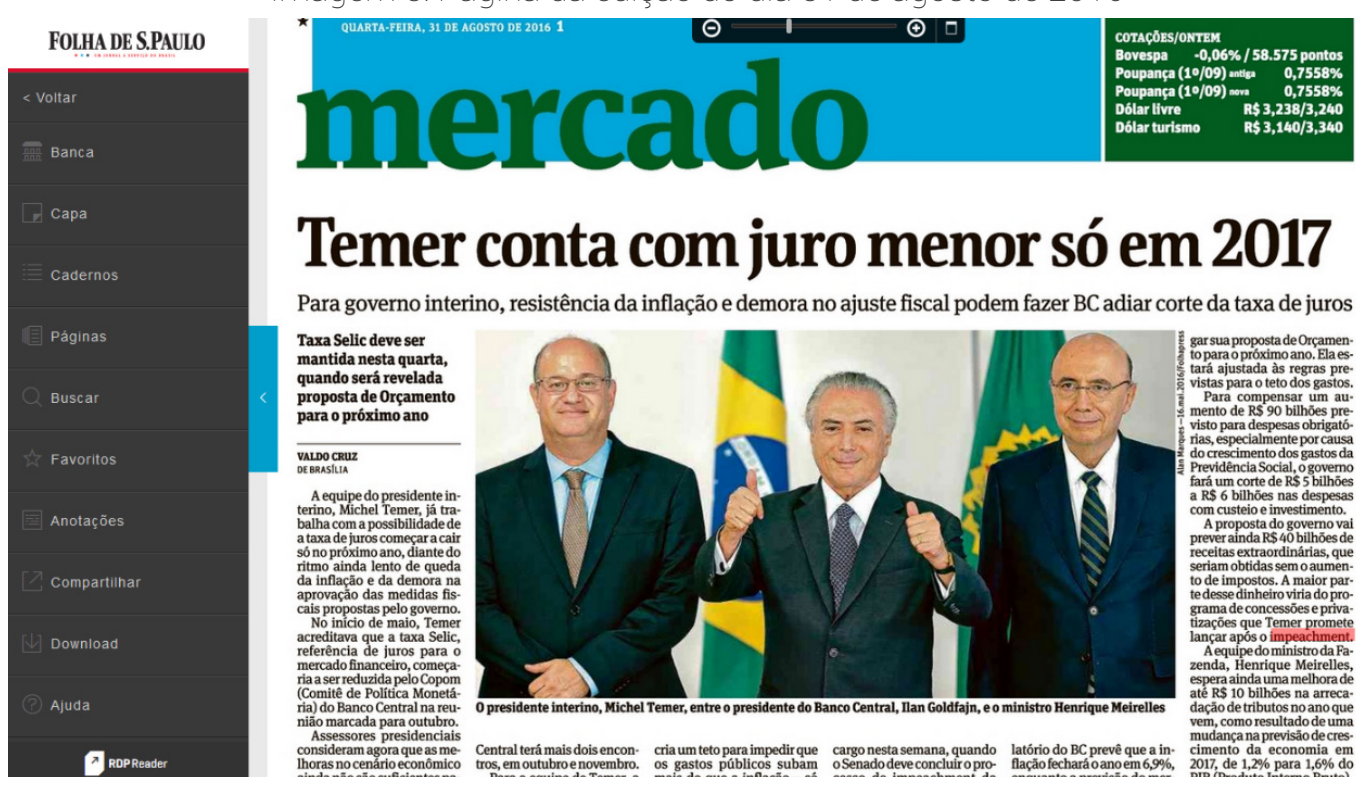

Desta forma, é preciso conscientizar o público leitor sobre a importância de uma análise crítica e reflexiva, na qual se analisa também o não dito, pois existem muitas coisas subentendidas naquele discurso que não está implícito.

\section{Considerações finais}

Por meio das identificações e análises dos dispositivos de enquadramento, assim como das demais constatações que o estudo da teoria do enquadramento permite, conclui-se que o jornal Folha de São Paulo, edições do mês de agosto de 2016, visto que a votação final do processo aconteceu no dia 31 deste mês, enquadrou Dilma como a presidente que não sabe o que fazer diante da crise e que está sem saída. Nota-se que estes são os enquadramentos identificados pela pesquisa, embora não se descarte a existência de outros

Percebemos, ainda, a ocorrência dos processos de personalização e espetacularização da política, este último sendo percebido, principalmente, nas imagens que ilustraram os textos. Sendo a lógica da mídia o drama, o espetáculo, a encenação, o entretenimento, os temas políticos acabam sendo tratados sob a mesma ótica. Afinal, "a encenação da política é o fruto mais característico da peculiar aproximação entre política e massmedia" (GOMES, 1996, p. 30), em que "é preciso 
oferecer conteúdos capazes de garantir entretenimento suficiente para capturar a audiência de forma que esta possa, ao mesmo tempo, ser submetida à exibição dos produtos" (ibidem, p. 33).

Da mesma forma que em relação à personalização, entendemos que a espetacularização da política reduz as complexidades do campo político, além de contribuir para a alienação política dos leitores, assim como o acirramento de ódios e da polarização na política. Acreditamos que esse processo merece pesquisas mais aprofundadas, pois, a princípio, apenas o relacionamos à lógica comercial da mídia, mas outros aspectos podem ser hipoteticamente levantados, como o despreparo dos profissionais da mídia acerca dos temas políticos, da administração pública e de economia.

Outro aspecto que podemos constatar é a ausência de regras básicas de jornalismo, como dar espaço para opiniões divergentes e a busca de imparcialidade - mesmo que saibamos da impossibilidade de o profissional ser completamente objetivo e imparcial, há cuidados que devem ser tomados pelos jornalistas para que suas opiniões pessoais e do veículo não se sobreponham às temáticas abordadas nas reportagens.

Conclui-se que a análise dos "dispositivos de enquadramento", propostos por Gamson e Modigliani (1989), permite que seja feito um estudo profícuo dos textos. A dissolução do texto em categorias, ou dispositivos, permite uma satisfatória análise do texto, possibilitando constatações que poderiam passar despercebidas em uma leitura não sistematizada.

Considerando o conceito de mediações introduzido por Jesús Martin-Barbero (2003) para abordar a interação entre os meios e seus públicos, podemos dizer que o mesmo ocorre com os jornais impressos com cobertura de economia. Eles não respondem unicamente a interesses comerciais ao determinar os modos e os ângulos de cobertura jornalística dos fatos econômicos, mas têm também de atender às demandas dos receptores e resignificá-las para que essa cobertura the tenha sentido. Ao analisar o jornalismo de economia verifica-se que, no Brasil, a partir da década de 1980 - a que deu início a uma "nova era" da cultura do consumo -, com os sucessivos planos que foram implementados na tentativa de conter a inflação, esse subcampo passou a tentar traduzir mais detalhadamente os fatos econômicos. A tendência persiste nos anos 1990 e se estabelece com a adoção por parte dos jornais da oferta de "jornalismo público" ou "cidadão" ou de "utilidade" para seus leitores. Assim, a partir de pesquisa teórica e empírica, é possível verificar que a narrativa da imprensa de economia adota um direcionamento mais superficial, o que compromete a compreensão do público é a superficialidade e a conduta tendenciosa no trato da informação. O jornalismo passou a atender a uma demanda crescente do leitor por informações sobre os impactos desses pacotes em suas vidas. O jornalista dessa área passa, então, a atuar voltado para atender a um leitor "consumidor-espectador-cidadão". E não se trata de uma mudança apenas para servir o leitor, com notícias mais didáticas, mas de uma estratégia de adaptação da imprensa, que se consolidou durante o regime militar e depois tem de encontrar novos rumos a partir da redemocratização. Tem de se adaptar, portanto, a uma necessidade de sobrevivência no mercado. E os pacotes econômicos foram momentos nos quais os jornais auto-afirmaram sua importância ao tentar desvendar os fatos desse campo específico do conhecimento e aproximá-los da compreensão dos leigos.

Em síntese diante dos dados apresentados é possível perceber que os motivos que resultaram no Impeachment Dilma Rousseff foram expostos de forma superficial pelo Jornal Folha de São Paulo, sendo tratados de forma rasa e tendenciosa, comprometendo o entendimento do público sobre o desenrolar do processo e veracidade dos fatos. Muitas vezes apoiando-se em discursos favoráveis a determinados grupos políticos. 


\section{Referências}

Jornais diários: Folha de S. Paulo - $1^{\circ}$ a 31 de agosto de 2016

ABREU, A. A.; LATTMAN-WELTMAN, F.; KORNIS, M. A. Mídia e Política no Brasil - jornalismo e ficção. Rio de Janeiro: Editora FGV, 2003.

MARTíN-BARBERO, J. Dos meios às mediações - comunicação, cultura e hegemonia. Rio de Janeiro: Ed. UFRJ, 2 a ed., 2003.

BASILE, S. Elementos do jornalismo econômico. Rio de Janeiro: Campus, 2002.

BIRD, S. E:; DARDENE, R. W. "Mito, registro e 'estórias': explorando as qualidades narrativas das notícias". In: Traquina, Nelson (org.). Jornalismo: questões, teorias e "estórias". Lisboa: Veja, 1993, p. 263-277.

FIBE, Lillian Witte. In: ABREU, Alzira Alves de \& ROCHA, Dora. Elas ocuparam as redações depoimentos ao CPDOC. Rio de Janeiro: Editora FGV, 1a edição 2006, 280p.

GAMSON, W.; MODIGLIANI, A. Media discurse and public opinion on nuclear power. a construcionist approach. American Journal of Sociology, v. 95, p. 1-37, 1989.

GOMES, W. Duas premissas para a compreensão da Política Espetáculo. In: Mídia, ética e política. Compós, 1996.

GRAMSCI, A. Cadernos do cárcere. São Paulo: Saraiva, 2002. v. 5.

KUCINSKI, B. Jornalismo Econômico. - 3 ed. rev. - São Paulo: Editora da Universidade de São Paulo, 2007.

LATTMAN-WELTMAN, Fernando, RAMOS, Plínio de Abreu \& CARNEIRO, José Alan Dias. A imprensa faz e desfaz um presidente. Rio de Janeiro: Nova Fronteira, 1994.

LEITÃO, Miriam. Jornalismo de economia depois da redemocratização. Entrevistadora: Hérica Lene. Rio de Janeiro, na residência da jornalista, na Gávea, em 15 de março de 2007.

LIPPMANN, W. Opinião pública. São Paulo: Vozes, 2008.

MARTÍN-BARBERO, J. Dos meios às mediações - comunicação, cultura e hegemonia. Rio de Janeiro: Ed. UFRJ, 2 a ed., 2003.

MEMÓRIA GLOBO. Jornal Nacional - a notícia faz história. Rio de Janeiro: Jorge Zahar Editor, 2004.

MENDONÇA, K. M. L. A salvação pelo espetáculo - mito do herói e política no Brasil. 